\title{
An overview of vitamin B12 and iron deficiencies as a risk factors in children with febrile seizure etiology
}

\author{
Sevim Turay, ${ }^{1}{ }^{(D)}$ Fatma Hanci, $^{2}{ }^{(D)}$ Sukriye Ozde $^{3}$ \\ ${ }^{1}$ Department of Pediatric Neurology, Duzce University, Medical Faculty, Duzce, Turkey \\ ${ }^{2}$ Department of Pediatric Neurology, Bolu Abant Izzet Baysal University, Medical Faculty, Bolu, Turkey \\ ${ }^{3}$ Department of Pediatrics, Duzce University, Medical Faculty, Duzce, Turkey
}

\section{ABSTRACT}

Aim: To determine serum iron, ferritin, folate, and vitamin B12 deficiency and associated hemoglobin (Hb), hematocrit (Hct), mean corpuscular volume (MCV), and red cell distribution width (RDW) values in children undergoing febrile seizure, and thus to reveal their potential etiological role.

Method: The serum iron, folate, vitamin B12, and ferritin, and Hb, Hct, MCV, and RDW values of 98 patients undergoing FS and presenting to the pediatric neurology department and of 64 control patients were retrieved retrospectively and compared. Patient group data were also compared within the group.

Results: Serum iron, ferritin, and vitamin B12 values were significantly lower in the patient group than in the control group. Intragroup comparison revealed higher RDW values in patients with more than three FS and in those with complicated seizures.

Conclusion: This is the first study to investigate the relationship between vitamin B12, folate, and iron deficiency and FS. It should be remembered that deficiencies in these micronutrients, which are not routinely investigated in patients presenting with FS, may play a role in the etiology, and that the frequency can decrease with treatment. It should also not be forgotten that FS patients with high RDW values may be at risk of frequent seizure recurrence.

Key words: Febrile seizure, nutrition, risk factors, vitamin B12, iron deficiencies, children, outcome.

$\triangle$ Dr. Sevim Turay

Department of Pediatric Neurology, Duzce University, Medical Faculty, Duzce, Turkey

E-mail: drsvm@yahoo.com

Received: 2021-02-18/Accepted: 2021-03-13

Published online: 2021-04-01

\section{Introduction}

Febrile seizure (FS) is an acute, symptomatic type of seizure most frequently seen in the first five years of childhood and affecting approximately $2-5 \%$ of children [1,2]. FS has been defined as seizures induced by fever in children older than one month, with no previous history of afebrile seizure, in the absence of any central nervous system infection, metabolic or electrolyte disorder, intoxication or trauma [3]. The American Academy of Pediatrics defines the age range at which FS is seen as 6-60 months [4]. The great majority of FS (65-70\%) present as simple FS [1]. Simple FS has good prognosis and is not linked to mortality, hemiplegia, or intellectual disability [5]. Generalized FS less than 15 min in duration and not repeated within $24 \mathrm{~h}$ are defined as simple FS $[1,6]$. However, although they are described as 'simple,' such seizures are nevertheless causes of grave anxiety for families [7].

Iron serves as a cofactor for various enzymes in the body and is an important micronutrient involved in the synthesis of deoxyribonucleic 
acid (DNA) and in the production of neurotransmitters and hormones. It is also an essential component of enzymes involved in a range of neurochemical reactions, such as myelin formation, brain energy metabolism, and neurotransmitter metabolism [8]. Numerous studies have shown that iron deficiency is associated with FS development in children $[9,10]$. Infants with iron deficiency are known to exhibit later cognitive, motor, social, emotional, and neurophysiological development than their peers, and studies have emphasized the importance of protecting the developing brain against iron deficiency [11]. This deficiency has been reported to cause poor physical performance through its role in muscle contraction and energy metabolism, and to lead to immune dysfunction due to its impact on the immune system [12]. This function impairment in the immune system can contribute to frequent fevers as a cause of increasing infections, and thus to more frequent FS.

Vitamin $\mathrm{B}_{12}$ cannot be synthesized in the human body, but together with folic acid it plays a role in DNA synthesis, and cell division and proliferation. Deficiency is generally associated with insufficient intake in diet. It causes a wide spectrum of symptoms by affecting various systems.

Described symptoms include growth and development delay, gastrointestinal motility disorders, hyperpigmentation, stomatitis, glossitis, orthostatic hypotension, tachycardia, irritability, lethargy, decreased activity, hypotonia, ataxia, hyporeflexia, tremor, seizure, movement disorders, vision disorders, loss of taste and smell, altered consciousness and memory, regression in acquired motor skills, paresthesia, vibration and proprioception disorders, psychiatric disorders, and coma [13,14]. Although neurological disorders and seizures have been described with serum vitamin $\mathrm{B}_{12}$ and folic acid deficiency [15-17], the numbers of studies showing the relationship with FS are limited.

Addressing treatable causes that may be involved in the etiology of FS can successfully prevent the disease. The purpose of the present study was to determine serum iron, ferritin, folate, and vitamin $\mathrm{B}_{12}$ deficiency and associated hemoglobin ( $\mathrm{Hb})$, hematocrit (Hct), mean corpuscular volume (MCV), and red cell distribution width (RDW) values in children undergoing FS, and thus to reveal their potential etiological role.

\section{Materials and methods}

The study was conducted at the Duzce University Faculty of Medicine Department of Pediatrics Division of Child Neurology, Turkey, between March 2019 and December 2020. It was approved by the local ethics committee (2020/248). The study was conducted in accordance with the principles of the Declaration of Helsinki. All patients and the institution were informed about the study and their written consents were obtained.

Ninety-eight patients and 64 healthy individuals as the control group identified retrospectively by scanning the hospital automation system were included in the study. Patients aged 1-60 months, with no previous history of afebrile seizure, with no history of trauma capable of resulting in seizure, in whom central nervous system infection and metabolic or electrolyte disorder were excluded, and with seizure induced only by fever were diagnosed with FS [3,4]. Generalized FS less than 15 min in duration and not recurring with $24 \mathrm{~h}$ was defined as simple FS [1,6]. Patients with FS attending the pediatric neurology clinic for routine controls at least two weeks after seizure 
and at a time when no disease was present, and whose $\mathrm{Hb}$, Hct, MCV, RDW, serum vitamin $\mathrm{B} 12$, folate, iron, and ferritin levels were investigated were included in the study. FS patients other than these 98 individuals, with insufficient available data, with histories of chronic disease or using vitamins were excluded from the study. The control group consisted of 64 children aged 1-60 months, attending the pediatric clinic for routine healthy child examination, whose $\mathrm{Hb}$, Hct, MCV, RDW, serum vitamin B12, folate, iron, and ferritin levels were investigated, with no history of disease or malnutrition, and not receiving additional vitamin supplementation. FS group age and gender, history of FS and epilepsy in the family, parental consanguinity, type of delivery, birth week, history of hospitalization in the infant, degree of fever at time of seizure, presence of complicated or simple FS, body weight, electroencephalogram (EEG) results, antiseizure treatment requirements, neurological examination findings at time of seizure, and cranial magnetic resonance imaging (CMRI) results were recorded. The patient and control groups were compared in terms of age, gender, and Hb, Hct, MCV, RDW, serum vitamin B12, folate, iron, and ferritin levels. The patient group was subdivided into children with three or fewer simple/complicated seizures and those with more than three seizures, and the same parameters were compared between these subgroups.

\section{Statistical analysis}

Continuous data were expressed as mean \pm SD (min-max), and categorical variables as frequency and percentage for each group. A range of statistical tests were applied, depending on normality of data distribution. The Kolmogorov-Smirnov test was used to determine the normality of distribution of the variables. The independent samples t-test was applied to normally distributed variables, while Pearson's chi-square test and Fisher's exact test were applied to categorical variables. The results were assessed within a $95 \%$ reliance and at a significance level of $p<0.05$. Analyses were performed on Statistical Package for Social Sciences 25.0 for Windows software (SPSS Inc., Chicago, IL, USA).

\section{Results}

The mean age of the patient group was $21 \pm 12$ months. Sixty-eight percent were boys and $32 \%$ girls. No family history of FS or epilepsy was present in $44 \%$ of the patients. A history of FS was present in $44.3 \%$ of families, of both FS and epilepsy in $6.2 \%$, and of epilepsy in $5.2 \%$. The parental consanguinity rate was $9.3 \%$. Additionally, $79.2 \%$ of patients were born on term, $21.8 \%$ preterm, $64.9 \%$ by cesarean section, and $35.1 \%$ by the normal vaginal pathway. A history of hospitalization in the neonatal period was present in $17.5 \%$ of patients. In terms of body temperature, $35.1 \%$ of patients experienced seizures at $37-37.9^{\circ} \mathrm{C}$, $36.1 \%$ at $38-38.9^{\circ} \mathrm{C}$, and $6.2 \%$ at more than $39^{\circ} \mathrm{C}$. Body temperature was unknown in $22.7 \%$ of cases. FS was simple in $72.2 \%$ of patients, complex in $25.8 \%$, and febrile status epilepticus in $2.1 \%$. In addition, $83.5 \%$ patients were normal weight, $8.2 \%$ were overweight, and $8.2 \%$ were underweight. EEG was not performed on $29.9 \%$ of patients, while EEG results were normal in $44.3 \%$ and abnormal in $25.8 \% \quad(18.6 \%$ generalized, $7.2 \%$ focal abnormality). Results were normal in 21 of the 22 patients on whom CMRI was performed, while dysgenesis of the corpus callosum splenium was determined in one. NO FS prophylaxis was being used by $52.6 \%$ of patients, $1.7 \%$ received intermittent 
prophylaxis, and $29.9 \%$ were on continuous prophylaxis. Neurological examinations at time of seizure were normal in $97.6 \%$ of patients. The distribution of all patient group categories is shown in Table 1.

The mean age of the control group was $26 \pm 14$ months, 33 (51.6\%) were boys and 31 (49.4\%) were girls. Age and gender distributions were similar between the two groups. Vitamin B12, iron and ferritin levels were significantly lower in the patient group compared to the control group. No difference was observed between folate, $\mathrm{Hb}, \mathrm{Hct}, \mathrm{MCV}$, or RDW values (Table 2).
When the patient group was subdivided into individuals with three or fewer seizures (80 patients) and those with more than three seizures, the only difference in the study parameters was observed in significantly higher RDW values among patients undergoing more than three seizures (Table 3). When the patient group was subdivided into simple and complicated FS, no significant difference was observed between the parameters, although RDW values were higher in the complicated FS group, but the difference was not statistically significant $(p=0.08)$ (Table 4).

Table 1. Demographic and clinical data of patients with febrile seizures.

\begin{tabular}{|c|c|c|c|}
\hline Variables & $\mathbf{N}(\%)$ or Mean \pm SD & Variables & N $(\%)$ or Mean \pm SD \\
\hline Age (month) & $21 \pm 12$ & FS classification & \\
\hline Gender & & Basic FS & $70(72.2)$ \\
\hline Female & $66(\% 68)$ & Complex FS & $25(25.8)$ \\
\hline Male & $31(\% 32)$ & FSE & $2(2.1)$ \\
\hline Family history & & Neurological examination & \\
\hline Absent & $43(44.3)$ & Normal & $93(97.9)$ \\
\hline $\mathrm{FC}$ & $43(44.3)$ & Abnormal & $4(2.1)$ \\
\hline Epilepsy & $5(5.2)$ & & \\
\hline Epilepsy and FC & $6(6.2)$ & \multirow{4}{*}{$\begin{array}{l}\text { Welgnt } \\
>97 p \\
<3 p \\
\text { Normal }\end{array}$} & \\
\hline Consanguinity & & & \multirow{3}{*}{$\begin{array}{c}8(8.2) \\
8(8.2) \\
81(83.5)\end{array}$} \\
\hline Absent & $88(90.7)$ & & \\
\hline Present & $9(9.3)$ & & \\
\hline Delivery type & & EEG result & \\
\hline $\mathrm{C} / \mathrm{S}$ & $63(64.9)$ & \multirow{5}{*}{$\begin{array}{l}\text { Normal } \\
\text { Generalized abnormality } \\
\text { Focal abnormality } \\
\text { n.a }\end{array}$} & \multirow{5}{*}{$\begin{aligned} 43 & (44.3) \\
18 & (18.6) \\
7 & (7.2) \\
29 & (29.9)\end{aligned}$} \\
\hline Normal & $34(35.1)$ & & \\
\hline \multicolumn{2}{|l|}{ Gestation week } & & \\
\hline Preterm & $21(21.8)$ & & \\
\hline Term & $76(79.2)$ & & \\
\hline NICU history & & CMRI result & \\
\hline Present & $17(17.5)$ & Normal & $20(20.6 \%)$ \\
\hline Absent & $80(82.5)$ & Abnormal & $2(2.06 \%)$ \\
\hline Body temperature $\left({ }^{\circ} \mathrm{C}\right)$ & & n.a. Treatment & $75(77.3 \%)$ \\
\hline Missing data & $22(22.7)$ & Absent & $51(52.6)$ \\
\hline $37-38$ & $34(35.1)$ & Intermittent prophylaxis & $17(17.5)$ \\
\hline $38-39$ & $35(36.1)$ & Continuous prophylaxis & $29(29.9)$ \\
\hline $39-40$ & $6(6.2)$ & & \\
\hline
\end{tabular}

FS: febrile seizure, C/S: cesarean section, NICU: newborn intensive care unit, EEG: electroencephalogram, CMRI: cranial magnetic resonance imaging, FSE: Febrile status epilepticus, n.a: not available. 
Table 2. A comparison of demographic characteristics and laboratory parameters between patients with febrile seizures and the control group.

\begin{tabular}{|c|c|c|c|}
\hline Variables & $\begin{array}{l}\text { Patient } \\
(\mathrm{N}=97)\end{array}$ & $\begin{array}{l}\text { Control } \\
(\mathrm{N}=64)\end{array}$ & $p$ \\
\hline Age(months) & $21 \pm 12$ & $26 \pm 14$ & $0.018^{a}$ \\
\hline \multicolumn{4}{|l|}{ Gender } \\
\hline Male & $66(\% 68)$ & $33(\% 51.6)$ & \multirow[t]{2}{*}{$0.047^{b}$} \\
\hline Female & $31(\% 32)$ & $31(\% 48.4)$ & \\
\hline Vitamin B12 & $373 \pm 176$ & $527 \pm 259$ & $<0.001^{a}$ \\
\hline Iron & $49 \pm 26$ & $65 \pm 22$ & $<0.001^{a}$ \\
\hline Ferritin & $28 \pm 32$ & $65 \pm 22$ & $0.001^{a}$ \\
\hline Folate & $13.1 \pm 5.2$ & $13.04 \pm 4.9$ & $0.8^{a}$ \\
\hline Hb & $11.7 \pm 1.1$ & $11.9 \pm 0.7$ & $0.3^{a}$ \\
\hline Het & $35 \pm 4$ & $34 \pm 4$ & $0.6^{a}$ \\
\hline MCV & $83 \pm 69$ & $75 \pm 10$ & $0.3^{a}$ \\
\hline RDW & $15.1 \pm 4.1$ & $14.5 \pm 1.6$ & $0.2^{\mathrm{a}}$ \\
\hline
\end{tabular}

Hb: hemoglobin, Hct: hematocrit, MCV: mean corpuscular volume, RDW: red cell distribution width. Data expressed as $n$ (\%). Bold $p$ values indicate statistical significance at $\alpha=0.05$.

${ }^{a}$ Independent samples $t$-test, ${ }^{b}$ Pearson's chi-square test.

Table 3. The relationship between seizure frequency and laboratory findings.

\begin{tabular}{|l|l|l|c|}
\hline \multirow{2}{*}{ Variables } & $\begin{array}{c}\text { Seizure } \\
\text { frequency } \\
\mathbf{3}(\mathbf{n}=\mathbf{8 0})\end{array}$ & $\begin{array}{c}\text { Seizure } \\
\text { frequency } \\
\mathbf{3}(\mathbf{n = 1 7})\end{array}$ & $\boldsymbol{p}$ \\
\hline Age(months) & $21.9 \pm 12.6$ & $16.6 \pm 11$ & $0.1^{a}$ \\
\hline \multirow{2}{*}{$\begin{array}{c}\text { Gender } \\
\text { Male } \\
\text { Female }\end{array}$} & $52(65 \%)$ & $14(82.6 \%)$ & \multirow{2}{*}{$0.1^{b}$} \\
\cline { 2 - 3 } Vitamin B12 & $362 \pm 162$ & $427 \pm 226$ & $0.16^{a}$ \\
\hline Iron & $26 \pm 23$ & $47 \pm 28$ & $0.8^{a}$ \\
\hline Ferritin & $26 \pm 23$ & $38 \pm 57$ & $0.14^{a}$ \\
\hline Folate & $13.1 \pm 5.2$ & $11.04 \pm 4.9$ & $0.13^{a}$ \\
\hline Hb & $11.7 \pm 1.1$ & $11.6 \pm 1.7$ & $0.5^{a}$ \\
\hline Hct & $35.1 \pm 4.3$ & $35.7 \pm 3.6$ & $0.6^{a}$ \\
\hline MCV & $85 \pm 75$ & $75 \pm 4$ & $0.5^{a}$ \\
\hline RDW & $14 \pm 1$ & $18 \pm 9$ & $<\mathbf{0 . 0 1}^{a}$ \\
\hline
\end{tabular}

$H b$ : hemoglobin, Hct: hematocrit, MCV: mean corpuscular volume, RDW: red cell distribution width Data expressed as $n$ (\%). Bold $p$ values indicate statistical significance at $\alpha=0.05$

${ }^{a}$ Independent samples $t$-test, ${ }^{b}$ Pearson's chi-square test.
Table 4. Relationships between type of febrile seizure and laboratory findings.

\begin{tabular}{|l|l|l|c|}
\hline Variables & $\begin{array}{c}\text { Basic FC } \\
(\mathbf{n = 7 0})\end{array}$ & $\begin{array}{c}\text { Complex } \\
\text { FC } \\
(\mathbf{n = 2 5})\end{array}$ & \multicolumn{1}{|c|}{$\boldsymbol{p}$} \\
\hline Age(month) & $22.1 \pm 12$ & $18.6 \pm 9.8$ & $0.23^{a}$ \\
\hline $\begin{array}{l}\text { Gender } \\
\text { Male } \\
\text { Female }\end{array}$ & $18(25.7 \%)$ & $12(48 \%)$ & \\
\cline { 2 - 3 } Vitamin B12 & $370 \pm 180$ & $370 \pm 176$ & $0.1^{b}$ \\
\hline Iron & $49.5 \pm 30$ & $49.7 \pm 30.5$ & $0.9^{a}$ \\
\hline Ferritin & $22 \pm 16$ & $41 \pm 54$ & $0.01^{a}$ \\
\hline Folate & $12.1 \pm 4.2$ & $13.9 \pm 6.4$ & $0.3^{a}$ \\
\hline Hb & $11.7 \pm 1.2$ & $11.6 \pm 0.9$ & $0.6^{a}$ \\
\hline Hct & $35.2 \pm 4.4$ & $35 \pm 3.6$ & $0.8^{a}$ \\
\hline MCV & $86 \pm 81$ & $77 \pm 5$ & $0.5^{a}$ \\
\hline RDW & $14 \pm 1$ & $16 \pm 7.8$ & $0.08^{a}$ \\
\hline
\end{tabular}

Hb: hemoglobin, Hct: hematocrit, MCV: mean corpuscular volume, RDW: red cell distribution width, FS: febrile seizure. Data expressed as $n$ (\%). Bold $p$ values indicate statistical significance.

\section{Discussion}

FS is the most common form of childhood seizure [1]. Despite its high prevalence, the etiopathogenesis is complex and has not yet been fully explained. Numerous factors, including age, gender, infections, immunizations, cytokines, ethnicity, low calcium, sodium, iron, and zinc levels, microcytic anemia, progression to nursery school, and a history of hospitalization exceeding 28 days in the neonatal period have all been implicated in the development of FS [1,18-23].

Iron and ferritin levels in this research were significantly lower in the patient group than in the control group. Studies performed over many years have emphasized the association between low iron levels and iron deficiency anemia (IDA) and FS. In 1996, Pisacane et al. determined higher IDA in patients with FS compared to both a hospital group and the 
normal population [10]. A case-control study from 2017 compared Hb, Hct, RDW, MCV, mean corpuscular hemoglobin $(\mathrm{MCH})$, and mean corpuscular hemoglobin concentration (MCHC) values between a 30-member FS group and a non-febrile control group enrolled at the same time. All values in the case group were significantly in favor of anemia [24]. No difference was observed between our patient and control groups in terms of $\mathrm{Hb}, \mathrm{Hct}, \mathrm{MCV}$, and RDW values.

In their meta-analysis of 17 studies, Kwak et al. determined a high level of correlation between IDA and FS (OR, 1.98; 95\% CI, 1.26-3.13; $p=0.003)$. While MCV (OR, 2.08; 95\% CI, 1.36-3.17; $p=0.001)$ and plasma ferritin $(O R$, 3.78; 95\% CI, 1.80-7.94; $p<0.001)$ exhibited moderate correlation with FS in some comparisons, no relationship was determined in two studies involving serum iron $(O R, 0.57$; 95\% CI, 0.24-1.37; $p=0.210$ ) [9].

A rat study reported a low seizure threshold in mice exposed to iron deficiency in the postnatal period, and showed that those mice were more susceptible to some types of seizure [25]. The mechanisms by which iron deficiency leads to seizure by causing excitatory-inhibitor imbalance are not yet fully understood.

A recent prospective study comparing 63 FS patients and a control group of 65 patients with nonconvulsive febrile illness reported significantly low serum iron, plasma ferritin, and transferrin saturation in the FS group. Consistent with the present study, iron deficiency was reported to increase the risk if FS even in the absence of IDA [26].

However, there are also studies reporting either the opposite or else no relationship. Kobrinsky et al. reported that iron deficiency can play a protective role in the context of FS [27]. Soheilipoor et al. compared 158 children with FS and 149 febrile children without seizures in terms of $\mathrm{Hb}$, Hct, RBC count, MCV, MCH, $\mathrm{MCHC}$, values and weight for age. Greater IDA was observed in febrile children without seizures, while no association was found between growth delay and FS [28]. Since no low-weight control group was included in the present study, no comparison was performed with growth delay. We observed no association between our patients' anemia-related values and those of the control group. In their metaanalysis, Habibian et al. observed an increased prevalence of anemia in patients with FS. The authors determined a moderately increased risk of FS with IDA in societies in which anemia is less common, compared to those in which it is only seen at high levels [29].

Serum vitamin B12 levels were significantly lower in the FS group than in the control group in the present study. However, there was no difference in serum folate levels between the two groups. The number of studies examining the relationship between serum vitamin B12 and folate levels and FS is limited. Vitamin B12 and folic acid serve on the methioninehomocysteine pathway responsible for the provision of methyl groups essential for DNA and protein synthesis. Vitamin B12 catalyzed the formation of methionine from homocysteine and the conversion of methylmalonyl coenzyme A (MMA) to succinyl coenzyme A [30,31]. Although the exact role of vitamin B12 in epileptogenesis is unclear, various mechanisms have been proposed in the mechanism, including MMA accumulation due to deficiency leading to impairment in myelin synthesis [30], increased homocysteine contributing to neurological dysfunction by way of oxidative stress [30-32], a decreased S-adenosylmethionine/ $\mathrm{S}$ adenosylhomocysteine ratio compromising the methylation pathway [33], and the protective effect of $\mathrm{S}$-adenosylmethionine against $\mathrm{N}$ - 
methyl aspartate receptor (NMDA)-mediated glutamate neurotoxicity [34].

Folate and cobalamin levels were investigated in both serum and cerebrospinal fluid (CSF) in 40 febrile children (18 FS, 22 non-FS) and in serum in 20 healthy children. Serum folate levels were significantly higher in all patients compared to the healthy group, the highest values being determined in FS patients. No difference was found in CSF levels between the FS and non-seizure febrile patients. This was interpreted as indicating that even if folate levels are elevated in serum, passage to the brain is prevented by the blood-brain barrier, and it therefore exhibits no seizure-triggering. Patients' serum cobalamin levels were lower than in the control group, while no difference was observed between the FS patients and the febrile non-seizure patients, and no association with FS could be established [35].

Similarly to the present study, Özkale et al. determined lower vitamin B12 levels in an FS group compared to a seizure-free group, while no difference was observed between the two groups in terms of serum folate, homocysteine, $\mathrm{Hb}, \mathrm{MCV}$, macrocytosis, or anemia. Folic acid levels were also lower among patients in the FS group with more than three seizures and in those experiencing seizures at a temperature range of $37.5-39^{\circ}$. The authors associated vitamin B12 deficiency with an increased disposition to FS, and folic acid deficiency with an increased frequency of FS [36].

When patients with FS frequencies of three or fewer were compared with those with frequencies of more than three, RDW values were significantly higher in the latter group. When our FS patients were divided into simple and complex seizures, no difference was determined between any parameters. RDW values were higher in the complicated group, but not significantly so. Considering that RDW values will naturally rise in case of iron, vitamin B12 and folate deficiency, elevation in RDW values in children undergoing frequent seizures may be useful in predicting vitamin B12, folate and iron deficiencies. In addition, the absence of significance among other parameters at intergroup comparison among the FS patients may be due to the unequal numbers in patient distribution.

The principal limitation of this study is its retrospective nature. We were therefore unable to evaluate parameters such as homocysteine, methylmalonic acid, transferrin saturation, and iron binding capacity. Our case number may also be regarded as insufficient in the light of the incidence of FS in the general community. However, anemia evaluation and serum iron, ferritin, folic acid, and vitamin B12 measurement are not routinely recommended in children presenting with FS. Considering that patients in which all parameters were fully examined were included in the study, the number is adequate.

\section{Conclusions}

The present study is the first study which investigates the relationship between $\mathrm{Hb}$, Hct, $\mathrm{MCV}, \mathrm{RDW}$ parameters and iron, vitamin B12, folate deficiencies with FS. Our findings show that although low serum ferritin, iron, and vitamin B12 levels do not cause anemia, they can increase the tendency to FS. We recommend that iron and vitamin $\mathrm{B} 12$ be examined in FS patients with RDW elevation due to the possibility of frequent seizure recurrence. Since the etiology of FS is multifactorial, the treatment of iron and vitamin B12 deficiencies may be effective in reducing the development of FS. Further prospective studies involving large case numbers are now needed in order to identify the mechanisms involved in FS development. 
Acknowledgments The authors would like to express special thanks to the Pediatrics Department of Duzce University, especially their lecturers and assistant doctors, for helping them throughout all stages of this work.

Funding: The author(s) received no financial support for the research, authorship, and/or publication of this article.

Conflict of Interest: The authors declare that they have no conflict of interest.

Ethical statement: The study was approved by the Local Ethics Committee of Düzce University (Date and decision no: 2020/248).

\section{Open Access Statement}

This is an open access journal which means that all content is freely available without charge to the user or his/her institution under the terms of the Creative Commons Attribution NonCommercial License

(http://creativecommons.org/licenses/bync/4.0). Users are allowed to read, download, copy, distribute, print, search, or link to the full texts of the articles, without asking prior permission from the publisher or the author.

\section{References}

[1]Seinfeld S, Shinnar S. Febrile Seizures. In: Swaiman KF, Aswal S, Ferriero DM, eds. Swaiman's Pediatric Neurology, Principles and Practice, 6th edn. Elsevier Saunders, UK/USA. 2017; pp 519-23.

[2]Berg AT. Febrile seizures and epilepsy: the contributions of epidemiology. Paediatr Perinat Epidemiol. 1992;6(2):145-52.

[3]Guidelines for Epidemiologic Studies on Epilepsy. Commission on epidemiology and prognosis, international league against epilepsy. Epilepsia. 1993;34(4): 592-96.

[4]Steering Committee on Quality Improvement and Management,
Subcommittee on Febrile Seizures American Academy of Pediatrics. Febrile seizures: clinical practice guideline for the long-term management of the child with simple febrile seizures. Pediatrics. 2008;121(6):1281-86.

[5]Subcommittee on Febrile seizures, American Academy of Pediatrics. Neurodiagnostic evaluation of the child with a simple febrile seizure. Pediatrics. 2011;127(2):389-94.

[6]Nelson KB, Ellenberg JH. Predictors of epilepsy in children who have experienced febrile seizures. N Engl J Med. 1976; 295(19): 1029 -33.

[7]Paul SP, Rogers E, Wilkinson R, et al. Management of febrile convulsion in children. Emerg Nurse. 2015;23(2): 18-25.

[8]Rouault TA, Cooperman S. Brain iron metabolism. Semin Pediatr Neurol. 2006;13(3):142-48.

[9]Kwak BO, Kim K, Kim SN, et al. Relationship between iron deficiency anemia and febrile seizures in children: a systematic review and metaanalysis. Seizure. 2017; 52:27-34.

[10]Pisacane A, Sansone R, Impagliazzo N, et al. Iron deficiency anaemia and febrile convulsions: case-control study in children under 2 years. $\mathrm{Br}$ Med J. 1996;10;313(7053):343.

[11]Lozoff B, Georgieff MK. Iron deficiency and brain development. Semin Pediatr Neurol. 2006;13(3):158-65.

[12] Beard JL. Iron biology in immune function, muscle metabolism and neuronal functioning. J Nutr. 2001;131(2S-2):568-79.

[13] Serin HM, Arslan EA. Neurological symptoms of vitamin B12 deficiency: analysis of pediatric patients. Acta Clin Croat. 2019;58(2):295-302.

[14] Demir N, Koc A, Üstyol L, et al. Clinical and neurological findings of severe vitamin B12 
deficiency in infancy and importance of early diagnosis and treatment. J Paediatr Child Health. 2013;49(10):820-24.

[15] Kumar S . Recurrent seizures: an unusual manifestation of vitamin B12 deficiency. Neurol India. 2004;52(1):122-23.

[16] Glaser K, Girschick HJ, Schropp C, et al. Psychomotor development following early treatment of severe infantile vitamin B12 deficiency and West syndrome--is everything fine? A case report and review of literature. Brain Dev. 2015; 37(3):347-51.

[17]Naha K, Dasari S, Vivek G, et al. Vitamin $\mathrm{B}_{12}$ deficiency: an unusual cause for recurrent generalised seizures with pancytopaenia. BMJ Case Rep. 2012;3:2012:bcr2012006632.

[18] Ganesh R, Janakiraman L. Serum zinc levels in children with simple febrile seizure. Clin Pediatr (Phila). 2008;47(2):164-66.

[19] Sharawat IK, Singh J, Dawman L, et al. Evaluation of Risk Factors associated with First Episode Febrile Seizures. J Clin Diagn Res. 2016;10(5):SC10-13.

[20] Smith DK, Sadler KP, Benedum M. Febrile Seizures: Risks, Evaluation, and Prognosis. Am Fam Physician. 2019;99(7):445-50.

[21]Berg AT, Shinnar S, Hauser WA, et al. Predictors of recurrent febrile seizures: a metaanalytic review. J Pediatr 1990;116(3):329-37.

[22] Seinfeld S, Glauser TA, Shinnar S. Febrile Seizures. Pellock JM, Nordii DR, Sankar R, Wheless JW, eds. Pellock's Pediatric Epilepsy, 4th edn, New York: Demos Medical Publishing. 2017: pp.505-16.

[23] Mikati MA, Tchapyjnikov D. Febrile Seizures. Kliegman RM, Geme J St, Nelson Textbook of Pediatrics 21st Ed, Elsevier. 2019; pp.3092-94.

[24]Aziz KT, Ahmed N, Nagi AG. Iron Deficiency Anaemia As Risk Factor For
Simple Febrile Seizures: A Case Control Study. J Ayub Med Coll Abbottabad. 2017;29(2):316-19.

[25]Rudy M, Mayer-Proschel M. Iron Deficiency Affects Seizure Susceptibility in a Time and Sex Specific Manner. ASN Neuro. 2017;9(6):1759091417746521.

[26]Jang HN, Yoon HS, Lee E.H . Prospective case control study of iron deficiency and the risk of febrile seizures in children in South Korea. BMC Pediatr 2019;19(1): 309.

[27] Kobrinsky NL, Yager JY, Cheang MS, et al. Does iron deficiency raise the seizure threshold? J Child Neurol. 1995;10(2):1059.

[28] Soheilipoor F, Tavasoli A, Babasafari Renani Z. The Association between Failure to Thrive or Anemia and Febrile Seizures in Children between 6 Months to 6 Years Old Age. Iran J Child Neurol. 2018;12(3):86-93.

[29] Habibian N, Alipour A, Rezaianzadeh A. Association between Iron Deficiency Anemia and Febrile Convulsion in 3- to 60Month-Old Children: A Systematic Review and Meta-Analysis. Iran J Med Sci. 2014;39(6):496-505.

[30] Miller A, Korem M, Almog R, et al. Vitamin B12, demyelination, remyelination and repair in multiple sclerosis. J Neurol Sci. 2005;233(1-2):93-97.

[31] Froese DS, Fowler B, Baumgartner MR. Vitamin $\mathrm{B}_{12}$, folate, and the methionine remethylation cycle-biochemistry, pathways, and regulation. J Inherit Metab Dis. 2019;42(4):673-85.

[32] Rosenblatt DS, Aspler AL, Shevell MI, et al. Clinical heterogeneity and prognosis in combined methylmalonic aciduria and homocystinuria. $\mathrm{J}$ Inherit Metab Dis. 1997;20(4): 528-38.

[33]Dror DK, Allen LH. Effect of vitamin $\mathrm{B}_{12}$ deficiency on neurodevelopment in 
infants: current knowledge and possible mechanisms, Nutrition Reviews. 2008;66(5),:250-55.

[34] Akaike A, Tamura Y, Sato Y, et al. Protective effects of a vitamin B12 analog, methylcobalamin, against glutamate cytotoxicity in cultured cortical neurons. Eur J Pharmacol. 1993; 241(1):1-6.

[35] Osifo BO, Lukanmbi FA, Familusi JB. Cerebrospinal fluid folate and cobalamin levels in febrile convulsion. J Neurol Sci. 1985;68(2-3):185-90.

[36] Özkale Y, Erol İ, Kılıçarslan B, et al. Serum vitamin B12, folic acid, and homocysteine levels in children with febrile seizure. Turk $\mathrm{J}$ Pediatr. 2015;57(4):345-52. 